\title{
Practical Realism: Against Standard Scientific Realism and Anti-Realism
}

\author{
Rein Vihalemm \\ Department of Philosophy, University of Tartu
}

\begin{abstract}
In this paper, the elaboration of the concept of practical realist philosophy of science which began in the author's previous papers is continued. It is argued that practical realism is opposed to standard scientific realism, on the one hand, and antirealism, on the other. Standard scientific realism is challengeable due to its abstract character, as being isolated from practice. It is based on a metaphysical-ontological presupposition which raises the problem of the God's Eye point of view (as it was called by Hilary Putnam). Joseph Rouse's conception of science as practice, Sami Pihlström's pragmatic realism, and even Ilkka Niiniluoto's critical scientific realism are interpreted as practical realist conceptions. Pihlström suggests that the contemporary scientific realist should be prepared to accept the pragmatically naturalized Kantian transcendental perspective on realism. It is argued, however, that this realistically naturalized Kantianism can be nothing more than practical realism, as originated by Karl Marx.
\end{abstract}

Keywords: practical realism, pragmatic realism, standard scientific realism, critical scientific realism, Kantianism, Marxism

\section{Introductory remarks}

In recent decades in the philosophy of science a turn to practice has taken place. The new situation in the field can be characterized by a shift in focus away from theory because such a focus has been recognized as an unjustifiably narrow orientation towards theoretical physics only, at the same time neglecting research into the more general issue of how science actually works. This new tendency-to study science as it is actually practiced, or was practiced in history; and also to explore the nature of sciences other

Corresponding author's address: Rein Vihalemm, Department of Philosophy, Institute of Philosophy and Semiotics, University of Tartu, Ülikooli 18, 50090 Tartu, Estonia. Email: rein.vihalemm@ut.ee. 
than theoretical physics and to pursue other goals besides the logical reconstruction of physical theories-was originated by Thomas Kuhn. However, although Kuhn took actual science seriously and emphasised that science is not merely a logical, verbal and mathematical system-that it is created by human agents, scientists, who belong to a special community and act in a specific system or "world" with its characteristic mental and material cultures (in a "paradigm")-this does not mean that he succeeded in completely overcoming the old tradition and explicitly elaborating a new, practice-based conception of science.

One has to agree with Joseph Rouse's claims that Kuhn's ideas should be developed "further in the direction of an account of science as practice than he himself would be happy with" (Rouse 1987, 27) and that

Thomas Kuhn's The Structure of Scientific Revolutions has also been perhaps the most misunderstood. In particular, the depth of his criticism of the representationalist epistemology has often been overlooked. Kuhn has most commonly been read by philosophers as someone who ascribes a leading role to theory in science, who emphasizes the noncumulative character of theory change, and who denies the possibility of nonneutral criteria for assessing the cognitive worth of such changes. (Rouse 1987, 26)

Also, one should agree with Alexander Bird that:

in important respects Kuhn failed to break entirely with the preceding tradition. From the naturalistic perspective that has developed in "core philosophy" during the last two to three decades, which in due course spread to the philosophy of science, Kuhn's views are shot through with commitments to the Cartesian and empiricist traditions he saw himself to be rejecting. Furthermore, I argue that it is only partial rejection of positivism and empiricism that explains the radical appearance of the Kuhnian viewpoint-incommensurability, the conception of progress, the rejection of the concepts of truth and verisimilitude and, arguably the world change thesis, are consequences of positivist and empiricist views that Kuhn retained. (Bird 2000, $\mathrm{x}$ )

I would like to mention that the development of Kuhn's views-though his background was in theoretical physics - took place in close contact with chemistry and chemists or chemists turned non-traditional philosophers of science (James Conant, Leonard Nash, Michael Polanyi). ${ }^{1}$ Chemistry is an excellent example for analysing science as a special kind of socio-historical, practical activity, and for elaborating a practical realist philosophy of science

I have recently emphasised and discussed the influence of chemistry on the formation of Kuhn's ideas in my work (Vihalemm forthcoming a). 
as an alternative to both standard scientific realism and anti-realism. ${ }^{2}$ It can be said that, in many ways, the "new paradigm" in the philosophy of science emerged on the basis of chemistry. Though Roald Hoffmann asks in the title of his paper (2007) "What might philosophy of science look like if chemists built it?", one ought to acknowledge that, in a certain sense, chemistry has already greatly influenced the major change-the turn to practice-in the traditional philosophy of science. In chemistry it is obvious that-quoting a recent book by the philosophers and historians of chemistry, Bernadette Bensaude-Vincent and Jonathan Simon-"action comes first, before conceptualization, nomenclature, or theory"; "theory and substance are coproduced by the chemist in the laboratory" (Bensaude-Vincent and Simon $2008,6)$. In chemistry there is, so to speak, an intimate relationship between practical activity and realism (Bensaude-Vincent and Simon 2008, 209).

I have previously argued that Kuhn's paradigm should be interpreted as practice and started developing a philosophy of chemistry as a practicebased philosophy of science in works (written in Russian and Estonian) from the 1970 os and 1980s. In fact, this raises the question of how it was possible to develop a Marxist practice-based philosophy of science in the former Soviet Union. This is a long story and I cannot dwell on it here. ${ }^{3}$ But I am glad that recent developments in understanding science as practice and practical realism coincide with my long-term aspirations. In this paper, I continue the elaboration of the concept of practical realist philosophy of science that I started in (Vihalemm 2011b) and in several presentations, first at the Tartu workshop on the basis of which this volume was prepared, and thereafter at further seminars in Helsinki (at the Helsinki Collegium for Advanced Studies and in the Department of Philosophy of the University of Helsinki) where, on the one hand, there was a particularly good opportunity to continue discussions from Tartu on the relationship between practical realism and pragmatic realism, as developed by Sami Pihlström (2012), and, on the other hand, to discuss the problem of scientific realism that was thoroughly developed in Helsinki. First of all, thanks are due to Ilkka Niiniluoto whose critical scientific realism is undoubtedly one of the best known and most recognized positions on this issue (Niiniluoto 1999). I would like to show, however, that pragmatic realism as well as critical scientific realism could and - to my mind-even should agree with practical realism.

2 My presentation at the 14th Congress of Logic, Methodology and Philosophy of Science (Nancy, France, July 19-26, 2011) was devoted to this issue (Vihalemm 2011a).

3 I have talked about this elsewhere and have also written about it in (Vihalemm forthcoming b). 


\section{Practical realism, standard scientific realism, anti-realism}

In starting this section, it would first be appropriate to refer to the five theses on practical realism outlined in our Editorial (see p. 3). To speak about the world outside practice means to speak about something indefinable or illusory. It is only through practice that the objective world can really exist for humans. Therefore, knowledge must be regarded as the process of understanding how the world becomes defined in practice. One should say that science as practice is a way that we are engaged with the world and that allows the world to show how it can be identified in its own possible "versions". We are not "world makers". The world, however, does not consist of self-identifying objects; objects are identifiable-in principle, in a potentially infinite number of ways (in this sense they are inexhaustible, having innumerable aspects and connections with the rest of the world)-through practice. And practice is, in short, human activity as a social-historical, critically purposeful-normative, constructive, material interference with nature and society producing and reproducing the human world-culture-in nature.

As I have already said, practical realism is opposed to standard scientific realism, on the one hand, and antirealism, on the other. By standard scientific realism, I mean the conception according to which:

(1) there is a mind-independent world (reality) of observable and unobservable objects (the metaphysical-ontological aspect),

(2) the central notion is truth as correspondence between scientific statements (theories) and reality (the semantic aspect),

(3) it is possible to obtain knowledge about mind-independent reality (the epistemological aspect),

(4) truth is an essential aim of scientific inquiry (the methodological aspect).

To be an anti-realist in the debate about standard scientific realism means that at least one of these points is rejected and this is regarded as a rejection of (scientific) realism as such. Two main types of anti-realism are empiricistinstrumentalist and (social) constructivist.

Standard scientific realism is challengeable due to its abstract character, as being isolated from practice. It is based on a metaphysical-ontological presupposition which raises the problem of the God's Eye point of view (as it was called by Hilary Putnam). This problem is avoided in the case of empiricist-instrumentalist or constructivist anti-realism. Their criticism of 
realism, however, is not acceptable, as their context, too, is that of the traditional philosophy of science, which is language- and logic-centred and does not proceed from the practice of real science.

\section{Kantianism, Marxism, pragmatism}

In this section I will discuss first of all Sami Pihlström's conception of pragmatic realism and its relation to practical realism. I would like to mention that Pihlström has confirmed that his pragmatic realism agrees with the general characterisation of practical realism, given, in particular, in the aforementioned five theses. For my own part, I mostly agree with Pihlström: the pragmatist realism developed by him coincides to a very large extent with my practical realist views.

However, there is also a difference in our views. The difference is that Pihlström's research is devoted to the history and development of pragmatist philosophy, whereas I am interested in practice-based philosophy, which I see as originating with Marx. And, in this context, it should be recognised that the tradition of practice-based philosophy in general and especially the post-Kantian development of the problem of realism cannot be seen only from the perspective of pragmatism (see, e. g., Pihlström 2011, where "milestones" in the history of the problem of realism are presented). The origination of practice-based philosophical realism with Marx merits attention. (Incidentally, this concerns the practice-based approach not only in philosophy, but also (outside the context of this paper) in activity theory in psychology and beyond. As far as I know, the activity theory is well developed, e.g., in Helsinki and its origin in, and the relevance of, Marx's concept of practice are widely recognized.)

Pihlström suggests that the contemporary scientific realist should be prepared to accept the pragmatically naturalized Kantian transcendental perspective on realism. However, this naturalization of Kantian transcendentalism leaves his transcendental idealism in force. On my reading, a realistically naturalized Kantianism can be nothing more than practical realism. In his paper in this journal, Pihlström mentions-and I agree with him on thisthat my practical realism differs from his approach "in being more distant from the Kantian transcendental concerns-and therefore in a sense 'more realistic' (and at least not idealistic even in a reinterpreted sense)" (Pihlström 2012, 88).

Indeed, though I agree in a sense, namely in a practical-realistically reinterpreted sense, with "Kantian transcendental concerns," I cannot agree-it seems to me even a contradictio in adjecto - that this practical-realistically reinterpreted Kantian transcendentalism might be in some sense still ideal- 
istic. ${ }^{4}$ In the practice-based approach, originated by Marx, the expression practical realism is actually synonymous with practical materialism and in a sense also with practical naturalism. Materialism or naturalism does not mean here, of course, some kind of physicalistic or biologistic reductionism; it means the rejection of not only subjective idealism, but of objective idealism and dualism as well.

Pihlström continues in the paper to which we just referred:

Yet, it seems to me that a very basic transcendental issue concerning the practice-laden representability and experienceability of reality must be taken up from the perspective of practical realism, too: according to Vihalemm's practical realism, scientific objects can, after all, only be identified within scientific practices. Thus, it would seem - at least this rearticulation should be available to the "Kantian pragmatist" - that practices provide transcendental (contextual) conditions for the possibility of there being scientifically representable objects at all-for us. This also sounds very much like Dewey's (e.g., Dewey1929) view that scientific objects are not "ready-made" prior to inquiry but rather arise out of, or are constructed and/or identified in the course of, inquiry (Pihlström 2012, 88-89).

This is right. However, I see this just as the practical-realistically reinterpreted Kantianism that was also reached by the pragmatists, at least by Dewey and, of course, by Pihlström himself.

${ }^{4}$ Incidentally, Kenneth Westphal argues in his (2004) and several articles that "transcendental idealism is not, pace Kant, required for" the critical tasks of his philosophy and that "Kant's transcendental idealism is unsupported, false, nor can it fulfill some of the key aims Kant claims it alone can fulfill..." (Westphal 2004, 34). He offers a positive reinterpretation of Kant's critical philosophy as an unrestricted realism, or as he puts it, "a genuinely transcendental proof of realism sans phrase" (Westphal 2004, 35). Westphal shows that Kant's defence of transcendental idealism was based on a "disjunctive syllogism: either empiricism or transcendental idealism is true; empiricism faces insuperable difficulties; therefore transcendental idealism is true. The problem with this disjunctive syllogism is Kant's inadequate effort to examine and defend its major premise" (Westphal 2004, 83). According to Westphal, Kant did not consider the realist alternative. Pihlström, however, disagrees with Westphal on this point (Pihlström 2009, 182-183, fn 34) and agrees with the "articulation of transcendental idealism as a standpoint based on an anthropocentric, in contrast to transcendental realism's theocentric, conception of cognition ... This is explicitly connected with Putnam's contrast between internal and metaphysical realism - thus, we can see that the roots of the debate between metaphysical realism and its alternatives (including pragmatism) lie in the Kantian contrast between transcendental realism and transcendental idealism" (Pihlström 2009, 64-65). But here I am happy to clarify that Kenneth Westphal confirmed to me in personal communication that his realism sans phrase cannot be interpreted as metaphysical realism (presupposing the God's Eye point of view). He is in entire agreement with practical realism that there is no "pre-made world"; our ontology of nature can only result from scientific inquiry which is a practice, or a host of practices, of inquiry. 
It must be acknowledged, moreover, that it was Marx who first showed, opposing hitherto-existing materialism and idealism in philosophy (see the Theses on Feuerbach), that the world, "the thing [Gegenstand], reality, sensuousness," was in pre-Marxist materialism "conceived only in the form of the object [Objekt] or of intuition [Anschauung], but not as human sensuous activity, practice, not subjectively. Hence it happened that the active side, in contradistinction to materialism, was developed by idealism-but only abstractly, since, of course, idealism does not know real, sensuous activity as such" (Marx 1845). Marx emphasised in the second thesis: "The dispute over the reality or non-reality of thinking which is isolated from practice is a purely scholastic question" (Marx 1845). And in the Economic and Philosophical Manuscripts of 1844 (the section on the Critique of Hegel's Philosophy in General), he wrote: “...nature ..., taken abstractly, for itself-nature fixed in isolation from man-is nothing for man" (Marx 1844).

In Marxist philosophy, the subject and its practical activity, becoming a legitimate part of material reality (objective reality), also have objective characteristics. Thus, the subject is included in material reality as a specific component and no longer has consciousness as its only constituent property. The impact of practice on reality is brought about not from "outside" but from "inside" the latter. This is the impact of one form of objective reality on another-the impact of reality "in the form of activity" on reality "in the form of an object". The traditional model of cognition, of obtaining knowledge, treats the subject and object as separate realities in their concrete existence, the characteristics of which are independent of each other. In this model, activity is one of the subject's properties and, therefore, external to the object. Thus, the object is also provided external to the activity (independently of the latter); the problem is reduced to the movement, so to say, by the layers of this external object. The practice-based approach implies that practical activity has a more fundamental status than the status of individual objects-things. Concrete determination of the existence of individual objects in this case is determined by specifically defined activities in the context of which these objects-things appear as specific invariants.

Although Marx is usually ignored by pragmatists-and generally not referred to explicitly by other practice-based philosophers-I can refer to at least one pragmatist philosopher, namely Sidney Hook, who proceeded from Marx. He called his version of pragmatism "experimental naturalism," regarding it "as a continuation of what is soundest and most fruitful in Marx's philosophical outlook upon the world" (Hook 1976, 1). Hook found that Marx's critical theses about Ludwig Feuerbach constituted an important turning point in the history of philosophy (Hook 1976, 273). However, he also noted-and it seems he was right-that contemporary social scientists 
and philosophers "seek to develop their social [and practice-based-R.V.] philosophy on the basis of contemporary ethical values and available scientific knowledge. To the extent that Marx's genuine contributions to our understanding of history and society [and the category of practice-R.V.] have entered into the scientific [and philosophical-R.V.] tradition, nothing is lost by such reorientation. There is no more reason for calling oneself a Marxist in pursuing social sciences [and practice-based philosophy-R.V.] than calling oneself a Newtonian or Einsteinian in pursuing the physical sciencesbut there are obvious and weighty reasons grounded primarily in fidelity to truth... why Marx and his legacy should not be [neglected-R.V.] ..." (Hook 1976, 3).

\section{Practical realism on the problem of "thinghood": the TRH case as an example}

Here I would like to illustrate by an example-concerning the problem of "thinghood" - the practical realist approach to reality "in the form of activity." (As stated above, the concrete determination of the existence of individual objects-things is determined by specifically defined activities in the context of which these objects-things appear as specific invariants.)

Joseph Rouse puts the question of "thinghood" as in the following terms:

Belonging to the realm of possible determinations open within our practices is constitutive of a thing's being a thing at all. [...] [T]he things we ordinary encounter, with their many evident properties, so clearly belong to the real (because of their many determined interconnections with other things) that it is hard to see the possibility of their thinghood's being in question. It is the same sort of difficulty we have in trying to hear or see sentences in a language we already know as meaningless sound or random marks on a page. What we need for clarification is an example where "thinghood" is in question. Fortunately, we have at hand a revealing case. (Rouse 1987, 163)

Rouse refers here to a case which has become known through a book Laboratory Life: The Construction of Scientific Facts (Latour and Woolgar 1979) by the supposed social constructivist anti-realists, Bruno Latour and Steve Woolgar. This case concerns the determination of the chemical structure of the thyrotropin releasing hormone (or factor) - TRH (or TRF). Roger Guillemin and Andrew Schally were jointly awarded the Nobel Prize in medicine in 1977 for their work on this determination. The problem of the "thinghood" (in the sense of being a definite chemical substance) of TRH was resolved accordingly. Initially, the name "TRH" was used to designate, as Rouse $(1987,163)$ writes, "whatever was physiologically active (in this case stimulating the pituitary glands of rats to produce and release thyrotropin) in 
certain chromatographically isolated fractions of the hypothalami of sheep or pigs. But it was an open question whether TRH actually denoted a thing rather than an unstable artifact of the investigation." Further he underlines that the crucial point is:

not to show something to count as an $\mathrm{x}$ (in this case, as a chemical substance) is not to be a thing at all. The point is not that TRH magically became a real substance when its structure was successfully determined. At that point it was recognized as having been a substance all along, in large part because it had the appropriate sort of property (in this case a molecular structure). But this condition for being a substance was made possible historically by the evolving complex of practices that made molecular structures intelligible and allowed them to reveal themselves. Only within such a field of practices could having such a structure be a condition for counting as real. (Rouse 1987, 164)

This case study from Latour's and Woolgar's book is quite often referred to in debates about realism and anti-realism. The interpretation of this issue by Rouse and several other authors is in the spirit of practical realism. ${ }^{5}$

Latour's and Woolgar's work is analysed, for instance, in a paper by Ian Hacking (1988) (he later considers the TRH case in his (1999) "The Social Construction of What?", too). I agree with Hacking who finds-to my mind, similarly to Rouse-that

there is .... a realist version of the kind of irrealism espoused by Latour and Woolgar. When I speak of realism, I do not mean realism with all its philosophical accretions. For example, many scientific realists argue for realism in terms of our converging on the one great truth,

5 Rouse has been criticized in (Kochan 2011) for his somewhat confusing position on the issue of realism. The critic argues that "Joseph Rouse has drawn from Heidegger's early philosophy to develop what he calls 'a practical hermeneutics of science", but "suppresses Heidegger's distinction between existence and essence" (Kochan 2011, 81). Therefore, there is "a crucial difference between Rouse and Heidegger: whereas Rouse attempts to collapse the difference between an entity's existence and its meaning, Heidegger keeps the two separate. As a result, unlike Rouse, Heidegger can allow that entities exist without also being the subjects of interpretation. On this basis, I suggest that Heidegger can accommodate the core realist doctrine of independent existence, and hence the natural intuition that scientists 'get at the real'. ... Rouse's failure to accept the realist doctrine of independent existence introduces a debilitating tension into his account of scientific practice. ... [Because he does not] distinguish the minimal realist doctrine that entities exist independently of our interpretations of them from the more ambitious realist doctrine, typical to scientific realists, that the determinate properties of such entities also exist independently of our interpretations, ... he unwittingly rejects the former along with the latter" (Kochan 2011, 82-83). I do not want to take a position on whether the critic has understood Rouse correctly, but I would like to point out that Kochan's reading of Heidegger proves to be in accordance with practical realism. 
or at least converging on something worth calling the truth. There is nothing, however, in the realist attitude that demands that there is a humanly expressible, uniquely richest statement of how the world is. (Hacking 1988, 290)

Work such as by Latour and Woolgar attracts attention by its irrealism or its constructivism. I can have no objection to that, having hung a very different book about experiment on a realist coat-hanger. But the interest of work such as Laboratory Life is not its irrealism, no more than the interest of my book is its experimental realism. What is great about Latour and Woolgar is their detailed and accurate attention to [it should be emphasised!-R.V.] experiment, a proper study for philosophers of science. (Hacking 1988, 291)

I also agree, however, with the critical appraisal of the philosopher of chemistry and technology, Davis Baird:

The picture Latour and Woolgar present of science is thoroughly literary. "Nature," with the help of "inscription devices" (i.e., instruments), produces literary outputs for scientists; scientists use these outputs, plus other literary resources (mail, telephone, preprints, etc.), to produce their own literary outputs. The material product the scientists happen to be investigating in Latour and Woolgar's study-a substance called "TRF"-becomes, on their reading, merely an instrumental good, "just one more of the many tools utilized as part of long research programmes" (Latour and Woolgar 1979, 148).... There is much to learn from Latour and Woolgar's Laboratory Life, as well as from the subsequent work of these authors. Indeed, Latour and Woolgar are important because they do attend to the material context of laboratory life. But, continuing a long tradition of text bias, they misdescribe the telos of science and technology exclusively in literary terms. (Baird 2004, 7)

The TRH case-as an example of practical realist opposition to standard scientific realism, on the one hand, and antirealism, on the other-can be summarised, referring to Rouse's aforementioned book (and slightly revising his text) $(1987,164-165)$, by posing and answering a series of questions along the following lines:

- Is there (really) such a thing as TRH, a substance whose molecules are composed of a chain of three amino acids and an amide group? Yes.

- Does its existence mean anything more than that we take account of TRH in our dealings with the world? - No.

- Could there be such a thing as TRH independent of certain practices (comprising also beliefs)? - No. 
- Within the context of those practices (comprising also beliefs), is it in any way dependent upon us whether a particular sample of material is (or contains) TRH? - No, except in the sense that we deliberately isolated this particular sample in order to obtain TRH.

- Is it true that TRH is (pyro)Glu-His-Pro-amide? - Yes.

- Does this identity mean anything more than that TRH is (pyro)GluHis-Pro-amide? - No. [As can be seen, "truth" is interpreted in a deflationary way.]

- Does the truth of this sentence explain why we can use TRH to stimulate the release of thyrotropin in rats? - No.

- Does the structure of TRH itself (together with a great deal of physiology) explain this effect? - Yes.

- Is the truth-or-falsity of 'TRH is (pyro)Glu-His-Pro-amide' (i.e., its being a meaningful candidate for truth or falsity, depending on whether some definite conditions obtain in the world) dependent upon our practices (including the language we speak)? - Yes.

- Is the truth of this statement dependent upon our practices, language, or beliefs? - No.

- Does ‘TRH' refer to TRH? - Yes.

- Does this reference mean anything more than that it is recognized by competent practitioners that the phrase 'TRH' is appropriately used in circumstances where a substance under discussion could in principle be identified as TRH? - No.

\section{Practical realism and critical scientific realism}

I agree with Ilkka Niiniluoto's criticism of Putnam's internal realism (Niiniluoto 1999). There is an essential difference between internal realism and practical realism (or Niiniluoto's critical scientific realism), as the former belongs to the tradition of Kantianism and cannot actually be qualified as realism at all. It should be acknowledged that the scientific account of the world is mediated by our practical and theoretical activity, which means, indeed, that our descriptions of the world, our "world-versions", are always relative to us. This does not imply, however, that the world itself (we can call it THE WORLD) is relative to us in the sense that our "world-versions" cannot be versions of THE WORLD (see Niiniluoto 1999, 218-226). Our 
scientific "world-versions", although they represent the world through conceptual frameworks or, more precisely, through paradigms in the Kuhnian sense, interpreted in turn as practices, still do tell us something about THE WORLD, as do the theories we have constructed, which, in their theoretical models, contain experimentally substantiated idealisations, since-referring to (Giere 1988, 81)-theoretical models are similar to real systems in specified respects and to specified degrees. As Niiniluoto $(1999,216)$ writes, "Conceptual frameworks are selected on the basis of our cognitive and practical purposes, and they can always be improved and made descriptively more complete". If we use the cookie-cutter metaphor, we can say, "A cake [THE WORLD-R.V.] can be sliced into pieces in a potentially infinite number of ways, and the resulting slices [say, natural kinds and laws of nature identified by us-R.V.] are human constructions made out of the parts [unidentified (complex, inexhaustible) objects, their properties and relations-R.V.] of the cake" (Niiniluoto 1999, 222).

However, from the practical realist point of view, Niiniluoto's approach, which is language- and logic-centred, seems to be too abstract as the context of practice is not thematized in it. More precisely, Niiniluoto's scientific realism is not (explicitly, at least) based on the conception of practice, though a few arguments from practice, made with reference to Marx (1845) and Engels (1886), are used (see Niiniluoto 1999, 39, 275). His critical scientific realism shares the standard scientific realist correspondence theory of truth according to which " $[t]$ ruth is a semantical relation between language and reality. Its meaning is given by a modern (Tarskian) version of the correspondence theory, and its best indicator is given by systematic enquiry using the methods of science" (Niiniluoto 1999, 10). Niiniluoto emphasises that this thesis separates the semantic realists from all kinds of pragmatists, who replace this realist account of truth with some epistemic surrogate (Niiniluoto 1999, 1112). This standard realist understanding of knowledge, the world and their relations outside practice should be revised, I believe.

In this connection, it seems appropriate to refer also to a paper by Pentti Määttänen, Experimental Practice and the Problem of Realism, in which the author criticises, by referring to John Dewey and emphasising the epistemic role of experimental interaction, the standard realist correspondence theory of truth.

The object independent of interaction can be achieved only by thought. If truth is now defined as a non-epistemic relation between these objects and statements about them, then truth is a relation whose both parts are accessible only by thought. [...] This criticism of classical correspondence does not, however, entail that the idea of correspondence should be rejected. The point is that the correspondence between knowledge and reality should be considered through inter- 
action and not only through perception. The reality manifests itself to us as objective conditions of action rather than causes of perception that cannot be perceived as such. (Määttänen 2003)

I cannot speak for pragmatists, but in practical realism, "truth" can be interpreted in a deflationary way and this interpretation is compatible with semantic realism. I agree with Joseph Rouse $(1987,147)$ that the reasons for accepting such deflation should be "perhaps somewhat different from those of most deflationists". He writes:

If I think that there are no substantive issues concerning truth, it is because I see the issues situated on the right side of the Tarski equivalence instead of the left. There are no fundamental philosophical issues peculiar to the concept of truth, for they are the same issues that arise concerning how things have any determinations at all. What is it for snow to be white? [Standard] [r] ealists think that things have such determinations independent of our practices, desires, and beliefs. [...] I think that what there is cannot be entirely separated from who we are and what we do. (Rouse 1987, 147-148)

Niiniluoto also emphasises-and this is the key point, I would like to stress - that it is important to make a distinction between unidentified and identified objects. THE WORLD contains unidentified objects which are identifiable, but not "self-identifying objects' in the bad metaphysical sense $[\ldots]$ : they are potentially identifiable by us [we can refer here to the aforementioned cookie-cutter metaphor-R.V.]" (Niiniluoto 1999, 221). I take THE WORLD to be unidentified objective reality or matter, objective in the absolute sense, i.e., independent from anyone's mind or consciousness; this absolute objectivity of its existence is its only defining characteristic, it is "matter as such". It was the "thing-in-itself" for Kant; however, for practical realists or materialists it is not ungraspable, but identifiable in its concrete forms of existence through practice, being itself a concrete way of objective existence.

In order to better understand the practical realist account of truth and reality, it is appropriate to quote Rouse (1987) again. It seems to me that Niiniluoto would agree with this. Rouse writes:

The predicate 'true' can be applied only to sentences in language. [... ] [A language] connects assertions with truth conditions but does not determine whether those conditions obtain. Similarly, what exists depends upon the field of meaningful interaction and interpretation within which things can be encountered. This configuration of practices (including, of course, linguistic practice) allows things to show themselves as they are in a variety of respects. [...] The recognition that the possible ways a thing can be depends upon the configuration 
of practices within which they become manifest should therefore not reinforce the realist's fear that we are being described as 'world makers'. The language we speak does not determine which of its sentences are true. The practices that constitute our 'world' likewise do not determine which things exist, with what properties. (Rouse 1987, 160161).

In fact, Niiniluoto also refers (Niiniluoto 1999, 275) to Engels' oftenquoted statement on practice as the criterion of truth which is relevant here:

If we are able to prove the correctness of our conception of a natural process by making it ourselves, bringing it into being out of its conditions and making it serve our own purposes into the bargain, then there is an end to the Kantian ungraspable 'thing-in-itself'. The chemical substances produced in the bodies of plants and animals remained just such 'things-in-themselves' until organic chemistry began to produce them one after another, whereupon the 'thing-in-itself' became a thing for us... (Engels 1886)

Thus, we return to Marxist practice-based realism.

\section{Acknowledgments}

My research was supported by the Estonian Science Foundation grant no. 7946. Earlier versions of this paper were presented at a workshop in Tartu (in June, 2011) and seminars in Helsinki (at the Helsinki Collegium for Advanced Studies in November, 2011 and in the Department of Philosophy of the University of Helsinki in December, 2011). I am grateful to the participants of the workshop and the seminars for discussion and very useful comments. I would especially like to thank Sami Pihlström, Rom Harré, Joseph Rouse, Tarja Knuuttila, Kenneth Westphal, Ilkka Niiniluoto, Pentti Määttänen, and Matti Sintonen. I am also grateful for receiving a fellowship at the Helsinki Collegium for Advanced Studies, granted by the Kone Foundation.

\section{Bibliography}

Baird, D. (2004). Thing Knowledge: A Philosophy of Scientific Instruments, University of California Press, Berkeley.

Bensaude-Vincent, B. and Simon, J. (2008). Chemistry: The Impure Science, Imperial College Press, London.

Bird, A. (2000). Thomas Kuhn, Princeton University Press, Princeton.

Engels, F. (1886). Ludwig Feuerbach and the end of classical German philosophy. 
URL: http://www.marxists.org/archive/marx/works/download/Marx_ Ludwig_Feurbach_and_the_End_of_German_Classical_Philosop.pdf

Giere, R. N. (1988). Explaining Science: A Cognitive Approach, University of Chicago Press, Chicago.

Hacking, I. (1988). The participant irrealist at large in the laboratory, British Journal for the Philosophy of Science 39: 177-294.

Hacking, I. (1999). The Social Construction of What?, Harvard University Press, Cambridge.

Hoffmann, R. (2007). What might philosophy of science look like if chemists built it?, Synthese 155: 321-336.

Hook, S. (1976). From Hegel to Marx: Studies in the Intellectual Development of Karl Marx, 5th edn, University of Michigan Press, Ann Arbor.

Kochan, J. (2011). Getting real with Rouse, Perspectives on Science 19: 81-115.

Latour, B. and Woolgar, S. (1979). Laboratory Life: The Construction of Scientific Facts, Sage, London.

Marx, K. (1844). Economic and Philosophical Manuscripts of 1844.

URL: http://www.marxists.org/archive/marx/works/1844/manuscripts/ hegel.htm

Marx, K. (1845). Theses on Feuerbach.

URL: http://chss.montclair.edu/English/furr/gned/marxtonf45.pdf

Määttänen, P. (2003). Experimental practice and the problem of realism. Paper delivered at the 12th LMPS Congress, Oviedo.

Niiniluoto, I. (1999). Critical Scientific Realism, Oxford University Press, New York.

Pihlström, S. (2009). Pragmatist Metaphysics: An Essay on the Ethical Grounds of Ontology, Continuum International Publishing Grupp, London.

Pihlström, S. (2011). The problem of realism, from a pragmatist point of view: On the contextuality of scheme-(in)dependence in pragmatism, in R. Frega (ed.), Pragmatist Epistemologies, Lexington, Lanham, pp. 103126.

Pihlström, S. (2012). Toward pragmatically naturalized transcendental philosophy of scientific inquiry and pragmatic scientific realism, Studia Philosophica Estonica 5.2: 79-94.

Rouse, J. (1987). Knowledge and Power: Toward a Political Philosophy of Science, Cornell University Press, Ithaca.

Vihalemm, R. (2011a). Philosophy of chemistry against standard scientific 
realism and anti-realism.

URL:

http://www.univ-nancy2.fr/poincare/documents/ CLMPS2011ABSTRACTS/14thCLMPS2011_C4_Vihalemm.pdf

Vihalemm, R. (2011b). Towards a practical realist philosophy of science, Baltic Journal of European Studies 1: 46-6o.

Vihalemm, R. (forthcoming a). What is a scientific concept: Some considerations concerning chemistry in practical realist philosophy of science, in J.-P. Llored (ed.), Philosophy of Chemistry: Practices, Methodologies and Concepts, Cambridge Scholars Publishing, Cambridge.

Vihalemm, R. (forthcoming b). Theoretical philosophy and philosophy of science in the Soviet times: Some remarks on the example of Estonia in 1960-1990, Studia Philosophica Estonica 3.2.

Westphal, K. R. (2004). Kant's Transcendental Proof of Realism, Cambridge University Press, Cambridge. 